\title{
Self-Regulation Skills: Several Ways of Helping Students Develop Self-Regulated Learning
}

\author{
Tatiana Baranovskaya \\ National Research University Higher School of Economics
}

\begin{abstract}
Correspondence concerning this article should be addressed to Tatiana Baranovskaya, National Research University Higher School of Economics, Malaya Pionerskaya, 12, Moscow, Russian Federation, 115054.E-mail: tbaranovskaya@hse.ru
\end{abstract}

\begin{abstract}
Empirical research supports the long held assumption that self-control, self-esteem, and motivational orientations of adult language learners are important factors in their language learning behavior. However, precisely these variables influence the language learning process has yet to be investigated. The goal of this paper is to examine the role of how self-control, selfesteem and motivational orientations influence the English language learning process. Recent methodological advances and various theoretical frameworks that have guided the present research are considered in this paper. A special "bidirectional course" turning on teacherlearner interaction was designed - a communicative course which promoted learner autonomy. The results indicate that active involvement in learning, monitoring motivation, self-control and self-esteem are positively related to learning outcomes, demonstrating that the acquisition of self-regulation skills have a positive impact on the learning of English.
\end{abstract}

Keywords: motivation self-regulated learning, self-control, self-esteem

Self-regulation skills have long been the subject of research among educators, psychologists and sociologists. It is well-known that effective learning involves planning, goal-setting, progress monitoring and adapting if necessary. All these skills can be learnt, and by teaching them to students their learning can significantly improve. The aforementioned skills are closely related to the affective and self-regulatory variables of self-control, self-esteem and motivation. Without sufficient motivation, self-control and selfesteem, even those of exceptional ability cannot accomplish long-term goals, with an appropriate curriculum and effective teaching, alone, incapable of ensuring student achievement. To date, relatively little research has been directed toward the question of whether these skills can be developed over time. Therefore, the aim of this paper was to investigate selfcontrol, self-esteem and motivational orientations of adult learners at different language proficiency levels to understand how language learning behavior is influenced by these self-regulation skills. Motivation, self-regulation and self-esteem are key variables that may help increase and sustain second language learning.
Not all English language courses achieve the development in students of self-control, self-esteem and motivation. Within the ESOL field, further investigation into how to develop special training courses is still required. To address this oversight, a special bidirectional communicative course was designed - a student-oriented course which promoted learners' self-regulatory behavior. After reviewing the literature relevant to this research, a description of how the present study was carried out is provided followed by an interpretation of the results.

\section{Materials and Methods}

English as a Foreign Language studies have firmly established that theoretical approaches which focus on student self-control and motivation are of vital importance. They essentially include two major features in the processes of teaching and learning English. The first is that some teachers feel it vital to assert their dominant power in the classroom. In other words, they feel they need to be absolutely certain with 
regard to what to do in the classroom and how to deal with student behavior in every context. In contrast, other teachers have identified three important issues in education: 'The first is motivation, the second one is motivation and the third is motivation' (Swales, 2000). Certainly all teachers would agree that motivation is a significant factor in effective linguistic performance, which is considered the target of teaching a foreign language.

Motivation is considered to refer to self-confidence, enthusiasm, and the desire to understand and develop skills. It also stimulates behavior. The question arises as to whether motivation can be learnt and taught; that is, whether it is, at least in part, the responsibility of educators.

Empirical research in psychology indicates that there are two general types of motivation: extrinsic and intrinsic. Extrinsic motivation is a consequence of "external rewards and pressures" (Brown et al., 1998, p. 16). In other words, students learn due to external rewards like grades or prizes from parents or the desire to study abroad. In contrast, intrinsic motivation is dependent on personal goals and interests. In this case, students want to learn due to their natural interests and satisfaction. Intrinsic motivation can be enhanced by interesting materials offered by the teacher. In general, extrinsic motivation is "the-needto-learn" while intrinsic motivation is "the-want-tolearn" (Mezei, 2008). Motivation is closely related to self-control. It is generally believed that control is closely related to issues of discipline and punishment. As far as self-control is concerned, many teachers are accustomed to feeling it important to be dominant in the classroom in order to cope with "situations" that arise. Controlling is a classroom management technique that enables teachers to effectively manage their classes - especially large ones. Much attention has recently been paid to the fact that many teachers, tired of classroom dominance, have decided to switch roles with their students. Specifically, they are creating learning conditions whereby the students, themselves, assume a dominant role in learning English, with the teacher empowering them in the capacity of "language facilitator". In realizing that revolutionary "role-reversal", it is vitally important to help students develop self-control, which in turn may lead to selfregulated learning.

Self-regulated learning refers to the processes by which students attempt to monitor and control their own learning. There are many different models of self-regulated learning that propose different constructs and processes. However, these models do, in fact, share some basic assumptions about learning and regulation (Mezei, 2008).

According to Gabriella Mezei (2008), the most important models are the following three. "The first model considers learners as active constructive participants in the learning process. The second supposes that learners can potentially monitor, control, and regulate certain aspects of their own cognition, motivation, and behavior. The third general assumption that is made in these models of self-regulated learning is the goal. All models of regulation assume that there is some type against which comparisons are made in order to assess whether the process should continue as is or if some type of change is necessary. That is a general example for learning which assumes that individuals can set standards or goals to strive for in their learning, monitor their progress toward these goals, and then adapt and regulate their cognition, motivation, and behavior in order to reach their goals" (Mezei, 2008).

This paper follows the third model as it is clear that self-regulated learning is initiated by motivation. In this paper, self-regulated learning is treated as an active, constructive process whereby learners set goals for their learning and then attempt to monitor, regulate, and control them, guided and constrained by their own goals. The course presented in this paper was specifically designed to help learners self-regulate their learning, with the result that, different aspects of motivation were observed to have developed.

Learners can use different strategies to help them remember, understand, reason, and solve problems. Much work is devoted to the learning of these strategies, which students can use in academic contexts to comprehend text, to learn from lectures, to take notes, to solve math problems, and to write papers. In addition, considerable research has centered on strategies that learners can use to plan, monitor, and control their own learning process, indicating that the stronger the motivation is, the better the learning results are. Different motivational orientations refer to different types of motivation. Critically, an orientation on "the process" and on "the result" correspond to intrinsic motivation, whereas orientation on "teachers' assessment" and on "avoiding failure" are related to extrinsic motivation. In general, good self-regulating learners use a number of different strategies to control their cognition in ways that help them reach their goals.

Motivation includes the various strategies that individuals can use to try to control and regulate their own motivation and emotions. This can include strategies for boosting their self-confidence such as positive self-talk ("I know I can do this task") as well as strategies for trying to control their interest (e.g., making the task more interesting by making use of interesting materials, texts, cases).

Self-control is a "learning determinant" since it is closely related to motivation and involves learners' abilities to acquire the second language. 
Especially important are actual attempts to control motivational beliefs and emotions. This could involve increasing or decreasing effort on a task, as well as persisting on a task or giving up. Not only does motivation boost self-control, but self-control influences motivation as well. Help-seeking behavior is another important self-regulatory behavior. Good self-regulators usually adjust their effort levels to the task and their goals.

Such factors as self-esteem, self-control and motivation that can influence the development of self-regulation provide a solid foundation for selfregulated learning. Self-regulated learning is also time-consuming and quite difficult for some students. It is important that students are motivated to be self-regulating. Research of Paul R. Pintrich (1999) on the role of motivation in self-regulated learning has suggested three important generalizations about the relationships among motivation, self-control, selfesteem and self-regulated learning. First, students must feel self-efficacious or confident that they can do the tasks. If they feel they can accomplish the academic tasks, then they are much more likely to use various self-regulation strategies. Second, students must be interested in and value the educational tasks. Finally, students who are focused on goals of learning, understanding, and self-improvement are much more likely to be self-regulating than students who are pursuing other goals such as trying to look smarter than others or trying not to look stupid.

The research shows that motivation and self-control are closely related to self-esteem. Only when you can control your cognition can you assess it. Students must assess not only their performance but also their abilities to fulfill different tasks. Self-control helps in planning the action, foreseeing it and assessing it. All told, self-regulated learning is an important aspect of learning and achievement in academic contexts. Students who are self-regulating are much more likely to be successful in school; they want to learn more and achieve higher levels of performance.

Self-control, self-esteem and self-regulated learning cannot develop on the basis of "trial and error". There are models and strategies which help students to become self-regulated learners. Most models of self-regulating strategies include three general types of strategies: planning, controlling and assessing, and regulating (see, for example, Corno, 1986; Zimmerman \& Martinez-Pons, 1986, 1988.) Although these three types of strategies are highly related conceptually (Pintrich et al., 1999) and (e.g., Pintrich, 1989; Pintrich et al., 1993) and seem to be highly correlated empirically, they can be discussed separately as follows.

Planning activities include setting goals for studying, for example, skimming a text before reading, generating questions before reading a text, and doing a task analysis of the problem. These activities seem to help the learner plan and control their use of cognitive strategies and also seem to activate aspects of prior knowledge, making the organization and comprehension of the material much easier.

Controlling and assessing of one's thinking and academic behavior is an essential aspect of selfregulated learning. In order to be self-regulating, there must be some goal or standard against which comparisons are made in order to guide controlling and assessing. Weinstein and Mayer (1986) understand cognitive activities as partly the monitoring of comprehension, where students check their understanding against some self-set goal. Selfcontrolling and self-assessing include the tracking of attention while reading a text or listening to a lecture, self-testing through the use of questions about the text material to check for understanding, monitoring comprehension of a lecture and using test-taking strategies in examination situations.

Regulation strategies are closely tied to selfcontrolling and self-assessing strategies. As students monitor their learning and performance against some goal or criterion, this monitoring process suggests the need for regulation processes to bring behavior back in line with the goal. Self-control in its final part is always partly self-esteem. Self-esteem in its turn develops on the basis of self-control and at the same time it motivates the latter. It is clear that self-control and self-esteem can exist only together, influencing each other. If we consider reading, it is necessary for learners to ask themselves questions as they read in order to monitor their comprehension, and then go back and reread a portion of the text because this rereading is a regulatory strategy. Another type of selfregulatory strategy for reading occurs when a student slows the pace of their reading when confronted with more difficult or less familiar text. Of course, reviewing any aspect of course material that a student does not remember or understand that well while studying for an examination reflects a general selfregulatory strategy. During a test, skipping questions and returning to them later is another strategy that students can use to regulate their reading. All these strategies are assumed by this research to improve learning by helping students correct their studying behavior and repair deficits in their understanding.

Self-regulated learning is a process that assists students in managing their thoughts, behaviors, and emotions in order to successfully navigate their learning experiences. This process occurs when a student's purposeful actions and processes are directed towards the acquisition of information or skills. Generally, models of self-regulated learning are separated into phases. There is one model 
which discusses three distinct phases: forethought and planning, performance monitoring, and reflections on performance (Pintrich \& Zusho, 2002; Zimmerman, 2000). We based our research on this model. During the forethought and planning phase, students analyze the learning task and set specific goals toward completing that task. When students learn unfamiliar topics, however, they may not know the best ways to approach the task or what goals might be the most appropriate. Students are instructed on effective approaches in difficult cases.

Next, in the performance monitoring phase, students employ strategies to make progress on the learning task and monitor the effectiveness of those strategies as well as their motivation for continuing progress toward the goals of the task.

In the final reflection on performance phase, students evaluate their performance on the learning task with respect to the effectiveness of the strategies that they chose. During this stage, students also manage their emotions about the outcomes of the learning experience. These self-reflections then influence students' future planning and goals, initiating the cycle to begin again (Pintrich \& Zusho, 2002; Zimmerman, 2000).

Key studies that have been selected for this research are relevant to the topic of this paper; they problematize the main issues, help to build an argument and likely enable people to understand the topic of this paper. The study follows the approach of self-regulated learning which is methodologically relevant to this paper.

The present experiment was specifically designed to answer this study's research question: whether self-control, motivation and self-esteem influence the course of learning English.

60 first-year students attending the Higher School of Economics in Moscow, Russian Federation participated in this experiment. Their level of language proficiency ranged from A2 to B2 according to the Common European Framework of Reference. The procedure, which employed a classic pre-/post- test sequence, involved three stages. The first stage consisted of a "pre-test" aimed at establishing participants' selfregulatory skill baseline. The second stage of the experiment consisted of a "special" English training course aimed at promoting the development of selfregulatory skills in students. The third stage consisted of a "post-test" of self-regulatory skills necessary for skill level comparison before and after the training course.

In the first stage of the experiment, a questionnaire was administered to ascertain the students' baseline self-control, self-esteem and motivation levels. A small subset of this research focuses on self-control.
Table 1

Self-control

\begin{tabular}{lllll}
\hline Students & \multicolumn{4}{l}{ Levels of self-control } \\
& I & II & III & IV \\
\hline Number & - & 30 & 15 & 15 \\
\hline
\end{tabular}

According to (Zimneya, 1989), there are four levels of self-control in the learning of a foreign language. At the first level, the student who makes a mistake doesn't hear it. At the second level, the student doesn't correct his mistake himself but does so if the teacher shows him his mistake. At the third level, the student either makes no mistakes or corrects his mistakes himself. Lastly, at the fourth level, the student makes no mistakes.

In the pre-test phase of the experiment, students were asked to produce three oral and three written texts. The information we obtained is extremely useful for analyzing not only levels of self-control but also the learning characteristics of students as they potentially influence such individual characteristics as motivation and self-esteem (see Table 1).

The second pre-test subset focuses on motivation. The students completed a test in which they were asked about their interests and motivational orientations. They were given four response options to the following question: Which aspect of the foreign language learning process is most important to you? (a) the process of learning, (b) the result of learning, (c) the teacher's assessment, (d) avoiding failure.

The results of the experiment showed that the predominant orientation was on the result and avoidance of failure (refer to Table 2).

The third subset focused on self-esteem. At this stage of the experiment the students were administered the questionnaire. The results obtained, listed in Table 3, were used to determine students' self-esteem (Osnitskiy, 1986).

According to the information given in Table 3, we observed that $32 \%$ of the students relied on their own self-esteem while $25 \%$ thought that the marks they get correspond to their actual results. Most students (46\%) reported that their skills are adequately assessed, and, most important to students (32\%) is the way in which they assess their work themselves.

Having carried out these sets of experiments, a syllabus for the $1^{\text {st }}$ year students was designed. We did not focus solely on the development of the four traditional language skills, but instead concentrated on the implementation of competence-based teaching - the second stage of the experiment.

This specially-designed course was simply titled "English" and was described as an intermediate-level English for Special Academic Purposes (ESAP) course. 
Table 2

Number of Students by Motivational Orientation

\begin{tabular}{ll}
\hline Number of students & Motivational orientations \\
\hline 16 & Process \\
\hline 12 & Result \\
\hline 14 & Assessment of the teacher \\
\hline 18 & The avoidance of failure \\
\hline
\end{tabular}

The course, which spanned two terms, consisted of 96 reading hours.

In planning the course we had to deal with several problems. One of the biggest was that not all pupils in Russian schools pass the Unified State Exam in English, and, consequently, are not equal in terms of general knowledge. For this reason, they were subdivided into two groups according English proficiency level. To assess students' proficiency levels, the Oxford placement test was employed. In addition, students with different levels of self-control and self-esteem were in the same group. We therefore had to consider motivational aspects as well.

The course syllabus had been set in advance, independently of taking it and before students enrolled the course. The aim of the course was to enable students to develop competence in "English for Special Academic Purposes" and to raise their awareness of the possible role of English in their current and future learning and life. More specifically, the course was designed to enable an understanding of the role of English in modern life, to develop competence in using English in academic and professional environments, and to develop students' ability to monitor the effectiveness of their use of English (2). Our course had units devoted to General English and English for Economics (ESAP). By studying General English, students are meant to develop the four traditional language skills. The ESAP units provided students with Economics vocabulary, helping students to understand the language of specialty.

To achieve good academic results, a communicative integrated course was developed. It was based on cognitive aspects which favored comprehension and production of academic texts in the field of Economics. The students practiced speaking skills throughout the course. They were taught to give opinions and draw conclusions from selectede texts. The students were taught to write essays related to Economics, to plan their ideas and structure them, to read Economics journal articles in such a way as to identify the most newsworthy information (Swales, 2000). Students' auditory skills were developed by having them listen to different recordings. The students were asked to take notes in order to infer the meaning of unknown words from their context and to identify key words and main ideas stated in the text. Finally, reading was practiced through working on various types of texts in order to recognize connectors to distinguish relevant information and to identify general concepts.

Units devoted to Economics themes provided students with a wide range of vocabulary relevant to

Table 3

Results Used to Determine Students' Self-esteem

\begin{tabular}{|c|c|c|c|c|}
\hline Questions & Group I & Group II & Group III & Group IV \\
\hline \multicolumn{5}{|l|}{$\begin{array}{l}\text { Comparing the marks you get with your self-esteem, } \\
\text { what do you do? }\end{array}$} \\
\hline - $\quad$ Agree & 6 & 5 & 6 & 8 \\
\hline - Don't agree insisting on your own opinion & 4 & 6 & 7 & 7 \\
\hline - $\quad$ Don't pay attention to these marks & 5 & 4 & 2 & - \\
\hline \multicolumn{5}{|l|}{ When are you satisfied? } \\
\hline - $\quad$ Being overestimated & 5 & 4 & 3 & 2 \\
\hline - $\quad$ Being underestimated & 10 & 11 & 12 & 13 \\
\hline - $\quad$ Being estimated adequately & & & & \\
\hline \multicolumn{5}{|l|}{ Who do you think can estimate you better? } \\
\hline The teacher & 9 & 8 & 6 & 3 \\
\hline - $\quad$ You yourself & 6 & 7 & 8 & 9 \\
\hline - $\quad$ Your friends & & & 1 & 3 \\
\hline \multicolumn{5}{|l|}{ What is more important for you? } \\
\hline - The way you assess yourself & 8 & 7 & 9 & 8 \\
\hline - $\quad$ The way other people assess you & 7 & 8 & 6 & 7 \\
\hline
\end{tabular}


their future professional interests (Gilbert Maceda, 1991).

As far as Academic English is concerned, students were required to produce several assignments using Academic English. The most evident skills students to acquire were scanning, skimming, finding information, finding evidence to support claims in essays, interviewing, analyzing questionnaires, doing surveys and evaluating evidence. The aforementioned skills were new to the students, and it is clear from our results that more emphasis should be placed on them.

\section{Results}

\section{Pre-Test}

For the "pre-test", the students were subdivided into four subgroups according to their level of selfcontrol. The fourth group consisted of 15 students with "developed self-control", 8 students with a motivational orientation on "result", and 6 with a motivational orientation on "avoiding failure". 10 students appeared to have self-esteem oriented on "teachers' assessment", with the marks they get corresponding to their real results. Five students relied on their self-esteem, and one demonstrated a motivational orientation on the process.

The $3^{\text {rd }}$ group consisted of 15 students with the $3^{\text {rd }}$ level of self-control and 10 students with motivational orientation on teacher's assessment. Furthermore, 5 had motivational orientation on avoiding failure, 9 students think that their teacher can estimate them better, and 6 think that their own estimation is the most important.

The $2^{\text {nd }}$ group consisted of 15 students with the $2^{\text {nd }}$ level of self-control and 8 students oriented on the process. Moreover, 4 were oriented on the teachers' assessment, 3 on avoiding the failure, 5 with no regard for the teachers' assessment, and 10 who always agree with the teachers' assessment.

The $1^{\text {st }}$ group consisted of 15 students with the $2^{\text {nd }}$ level of self-control. 7 students were orientated on the process, 4 on avoiding the failure, and 4 on the result.

There were no students with the $1^{\text {st }}$ level of self-control.

According to the results we obtained, it became clear that the relationship between self-control and self-esteem and motivational orientations is significant $(r=0.78, p ; r=0.65, p)$.

High levels of self-control correspond to the motivational orientations on "Result", or to the development of adequate self-esteem. In contrast, low-levels of self-control correspond to the motivational orientation on teacher's assessment; that is, to inadequate levels of self-esteem $(r=0.76, p$; $r=0.79, p)$.

\section{Post-Test}

At the conclusion of the ESAP course the "posttest", consisting of the same battery of tests as in the "pre-test", was administered. The obtained results are shown in Table 4.

The results of this phase of the experiment show that, although the number of students in the $2^{\text {nd }}$ group decreased by 10 students, the number increased in the $3^{\text {rd }}$ group by 5 students and in the $4^{\text {th }}$ group by 5 students.

As shown in Table 5, the results of the experiment show that the predominant orientation on "Result" increased by 16 students, the orientation on "the process" decreased by four students, the orientation on "teacher's assessment" decreased by four students, and the orientation on "avoidance of failure" decreased by eight students.

The results obtained in Table 6 show that the number of students who like being overestimated decreased by 7 , and the number of students who rely on the teacher's assessment decreased by 8 . The number of students who rely on the way they assess themselves increased by 7 .

Considering the results of the "pre-test" and "posttest", we are tempted to postulate that, in accordance with our initial assumption, those students with a highlevel of self-control showed better communicative competence.

The ESAP course was based on a functional and interactive perspective on the nature of the English language. It sought to teach language in relation

Table 4

Self-control

\begin{tabular}{clccc}
\hline Students & \multicolumn{4}{l}{ Levels of self-control } \\
\hline & I & II & III & IV \\
\hline & - & 20 & 20 & 20 \\
\hline
\end{tabular}

Table 5

Number of Students by Motivational Orientation

\begin{tabular}{ll}
\hline Number of students & Motivational orientations \\
\hline 12 & Process \\
\hline 28 & Result \\
\hline 10 & Teacher's assessment \\
\hline 10 & The avoidance of failure \\
\hline
\end{tabular}


Table 6.

Self-esteem

\begin{tabular}{|c|c|c|c|c|c|}
\hline \multicolumn{2}{|c|}{ Questions } & Group I & Group II & Group III & Group IV \\
\hline \multicolumn{6}{|c|}{$\begin{array}{l}\text { Comparing the marks you get with your self-esteem, what do you } \\
\text { do? }\end{array}$} \\
\hline - & Agree & 4 & 3 & 4 & 4 \\
\hline - & Don't agree insisting on your own opinion & 9 & 10 & 11 & 1 \\
\hline- & Don't pay attention to these marks & 1 & 2 & - & - \\
\hline \multicolumn{6}{|c|}{ When are you satisfied? } \\
\hline - & Being overestimated & 3 & 3 & 1 & - \\
\hline - & Being underestimated & - & - & - & - \\
\hline- & Being estimated adequately & 12 & 12 & 14 & 15 \\
\hline \multicolumn{6}{|c|}{ Who do you think can estimate your better? } \\
\hline - & The teacher & 7 & 5 & 4 & 2 \\
\hline - & You yourself & 8 & 10 & 11 & 13 \\
\hline- & Your friends & - & - & - & - \\
\hline \multicolumn{6}{|c|}{ What is more important for you? } \\
\hline - & The way you assess yourself & 8 & 9 & 10 & 12 \\
\hline - & The way other people assess you & 7 & 6 & 5 & 3 \\
\hline
\end{tabular}

to the social contexts in which it is used. In this case, students were required to learn academic English, which was believed to be of use to students' professional development. Students were required to produce several assignments using Academic English at the end of the course consisting of oral presentations and written tasks. There are two reasons why competence-based language education was used. The first is that competence-based language education is an excellent method for validating the achievement of basic skills. The second is that competency-based language education, well-executed, practically ensures a correlation among self-control, self-esteem, and motivational orientations $(r=58, p<0.1)$.

All in all, the experiment showed that during the ESAP course students manifested strong relationships among self-control, self-esteem and motivationalorientations. However, those students with low marks on the results of the test did not pass the course with the same results as the students with good marks. Their results were lower. Clearly, students with better communicative competence obtained, on average, the best results on the final test. Nevertheless, a correlation between students with low marks as well as good marks and their motivational orientations, self-control and self-esteem has also been found $(r=67, p<0.1)$.

Research shows that self-regulated students are more engaged in their learning, are more selfmotivated and can positively influence their academic behavior and educational goals.

\section{Discussion and Conclusion}

Theoretical assumptions that self-control, selfesteem and motivation affect students' learning behavior have been supported by empirical research. The goal of this paper was to determine whether the variables of self-control, motivation and selfesteem are in any way related to the development of students' communicative competence. The reviewed studies also provide implications for future work. Students' ability to actively engage with the learning material, for example, setting appropriate goals, accurately monitoring their understanding and work, are critical competencies that should be a central aim within the education sector as a whole (OESD, PISA leaning for Tomorrow's World). Despite the importance of these processes, teachers rarely pay attention to them, with the result that they are not integrated into the high school foreign language classroom. However, the above-mentioned studies and the one herein presented provide ample evidence that self-control, motivation and self-esteem tend to elevate student communicative competence.

In sum, the results of our study indicate that self-regulation skills were developed during the specially designed English training course and positively influenced students' language acquisition in the investigated context. The study identified how self-control, self-esteem and motivation affected language awareness and the extent to which students 'self-regulation skills changed. Going forward, it would be interesting to explore how good self-regulators adjust their effort levels in light of language task difficulty and personal learning goals. And when pushed to the limit, we are also curious to know what patterns of task persistence and abandonment might be observed as a function of learner self-regulation. 


\section{References}

Brown, A., Bransford, J., Ferrara, R., \& Campione, J. (1983). Learning, remembering and understanding. In J. Flavell \& E. Markman (Eds.), Handbook of child psychology: Cognitive development, 3 (pp. 77-168). New York, NY: Wiley.

Corno, L. (1986). The metacognitive control components of self-regulated learning. Contemporary Educational Psychology, 11, 333-346.

Corno, L. (1993). The best-laid plans: Modern conceptions of volition and educational research. Educational Researcher, 22, 14-22.

de Corte, E., Mason, D. F., \& Verschaffel, L. (2011). Selfregulation of mathematical knowledge and skills. In B. J. Zimmerman \& D. H. Schunk (Eds.), Handbook of self-regulation of learning and performance (pp. 155-172). New York, NY: Routledge.

Gilbert Maceda, M. T. (1991). Igles para universitarios [English for university students]. Madrid, Spain: Universidad Nacional de Educacion a Distancia.

Graham, S., \& Harris, K. R. (2005). Improving the writing performance of young struggling writers: Theoretical and pragmatic research from the centre on accelerating student learning. Journal of Special Education, 39(1), 19-33.

Graham, S., Harris, K. R., \& Mason, L. (2004). Improving the writing performance, knowledge, and selfefficacy of struggling young writers: The effects of self-regulated strategy development. Contemporary Educational Psychology, 30, 207-241.

Harris, K. R., Graham, S., Mason, L. H., \& Sadler, B. (2002). Developing self-regulated writers. Theory into Practice, 41,110-115.

Hutchinson, T., \& Waters, A. (1987). English for specific purposes: A learning-centered approach. Cambridge, UK: Cambridge University Press.

Mezei, G. (2008). Motivation and self-regulated learning: A case-study of a pre-intermediate and an upper-intermediate adult student. Working Papers in Language Pedagogy, 2, 79-104.

Organisation for Economic Co-operation and Development. (2003). Learning for tomorrow's world. First Results from PISA 2003. Retrieved from http://www. oecd.org/education/school/programmeforinternationalstudentassessmentpisa/33917683.pdf

Osnitskiy, A. K. (1986). Samoreguljacija dejatel'nosti shkol'nika i formirovanie aktivnoj lichnosti [Selfregulation of learners' performance]. Moscow, USSR: Znanie.

Pintrich,P.R.(1999). The role of motivation in promoting and sustaining self-regulated learning. International Journal of Educational Research, 31, 459-470.
Pintrich, P. R. (2000). The role of global orientation in self-regulated learning. In M. Boekaerts, P. R. Pintrich \& M. Zeidner (Eds.), Handbook of selfregulation (pp. 451-502). San Diego, CA: Elsevier Academic Press.

Pintrich, P. R., Smith, D. A. F., Garcia, T., \& McKeachie, W. J. (1993). Reliability and predictive validity of the motivated strategies for learning questionnaire. Educational and Psychological Measurement, 53, 801-813.

Pintrich, P. R. (1989). The dynamic interplay of student motivation and cognition in the college classroom. In C. Ames \& M. Maehr (Eds.), Advances in motivation and achievement: Motivation enhancing environments (Vol. 6, pp. 117-160). Greenwich, CT: JAI Press.

Pintrich, P. R., \& de Groot, E. (1990). Motivational and self-regulated learning components of classroom academic performance. Journal of Educational Psychology, 82(1), 33-40. http://dx.doi. org/10.1037/0022-0663.82.1.33

Pintrich, P. R., Wolters, C., \& Baxter, G. (1999). Assessing metacognition and self-regulated learning. In G. Schraw (Ed.), Issues in the measurements of metacognition: Proceedings from the tenth BurosNebraska symposium on measurement and testing. Lincoln, NE: The University of Nebraska Press.

Swales, J. M. (2000). English in academic and research settings. Cambridge, UK: Cambridge University Press.

Weinstein, C. E., \& Mayer, R. E. (1986). The teaching of learning strategies. In M. Wittrock (Ed.), Handbook of research on teaching (pp. 315-327). New York, NY: Macmillan.

Zimmerman, B., \& Martinez-Pons, M. (1986). Development of a structured interview for assessing student use of self-regulated learning strategies. American Educational Research Journal, 23, 614-628.

Zimmerman, B. J., \& Martinez-Pons, M. (1990). Student differences in self-regulated learning: Relating grade, sex, and giftedness to self-efficacy and strategy use. Journal of Educational Psychology, 82, 51-59.

Zimmerman, B., \& Martinez-Pons, M. (1988). Construct validation of a strategy model of student selfregulated learning. Journal of Educational Psychology, 80, 284-290.

Zimmerman, B. J. (2000). Attaining self-regulation: A cognitive perspective. In M. Boekaerts, P. R. Pintrich \& M. Zeidner (Eds.), Handbook of self-regulation (pp. 13-39). San Diego, CA: Elsevier Academic Press.

Zimniya, I. A. (1989). Psihologiya obucheniya inostrannyim yazyikam [Psychology of teaching a foreign language]. Moscow, USSR: Prosveschenie. 


\section{Appendix A}

\section{Mathematical Statistics}

The coefficient of correlation according to Spirent /SRANK; SYSTEM/360 SSP-III; IBM

With the help of these programs the correlation between 2 vectors taking into account $n$-cases was checked/ the cases for each variable ranged from 1 to $n /$. It was necessary to calculate the differences of ranges.

$$
\left[\left(D=\sum_{i-1}^{n}(A)\right]_{i}-B_{i}\right)
$$

$A_{i}$ - is the $1^{\text {st }}$ vector of ranges, $B_{i}$ - is the $2^{\text {nd }}$ vector of ranges, $n$ - the number of ranges.

Then the correlation multiplier is calculated:

$$
T_{a}=\sum \frac{t^{2}-t}{12}
$$

For variable A

$$
T_{b}=\sum \frac{t^{2}-t}{12}
$$

For variable B

Then the correlation coefficient is:

$$
\begin{aligned}
& r_{S}=1-\frac{6 D}{n^{3}-n}, T_{a} \text { or } T_{b}=0 \\
& r_{S}=\frac{x+y-D}{2 \sqrt{x y}}, T_{a} \text { or } T_{b}=0
\end{aligned}
$$

Where

$$
\begin{aligned}
& x=\frac{n^{3}-n}{12}-T_{a} \\
& y=\frac{n^{3}-n}{12}-T_{b}
\end{aligned}
$$

$$
\text { Meaningfulness } r_{S}=t=r_{S} \sqrt{\frac{n-2}{1-r_{S}^{2}}}
$$

The calculations were carried out according to "Mathematical Statistics", Moscow, Dlin, Higher School, 1975, pp. 128-150.

Adequacy of all results was calculated according to CHISQ/System/ 360, Scientific Subroutine Package, Ver. III IBM (126). $x^{2}$ was calculated according to "Mathematical Methods in Social Sciences, P. Lazarfeld and N. Henry, 1973, Moscow, Progress (349).

The degrees of freedom are:

$$
d \cdot f=(n-1)(m-1)
$$

The following sums were calculated:

$$
\begin{gathered}
T_{i}=\sum_{j=1}^{m} A_{i j}, i=1, n \\
T_{i}=\sum_{i=1}^{m} A_{i j}, i=1, m \\
G T=\sum_{i=1}^{n} T_{i}
\end{gathered}
$$

$x^{2}$ is calculated for 2 cases:

$$
\text { 1. } x^{2}=\frac{G T\left(\frac{\frac{1}{2} A_{22}}{A_{11} A_{12}}-\frac{\frac{A_{12} A_{21}}{G T}}{2}\right)}{\left(A_{11}+A_{12}\right)\left(A_{21}+A_{22}\right)\left(A_{11}+A_{11}\right)\left(A_{12}+A_{22}\right)} \text { for table }
$$

2. $x^{2}=\sum_{i=1}^{n} \sum_{j=1}^{n} \frac{\left(A_{i j}-E_{i j}\right)}{E_{i j}}$, for the tables larger 2 in size $E_{i, j}=\frac{T_{i} T_{j}}{G T}$

The number got with the help of this equation corresponds to the validity coefficient of the data discussed in the research is equal to or more $95 \% / P \leqslant 0.05 /$. 